\title{
Effect of P-glycoprotein (P-gp) Inducers on Exposure of P-gp Substrates: Review of Clinical Drug-Drug Interaction Studies
}

\author{
Mohamed Elmeliegy $^{1}\left[\right.$ Manoli Vourvahis $^{2} \cdot$ Cen Guo $^{1} \cdot$ Diane D. Wang $^{1}$
}

Published online: 13 February 2020

(c) The Author(s) 2020

\begin{abstract}
Understanding transporter-mediated drug-drug interactions (DDIs) for investigational agents is important during drug development to assess DDI liability, its clinical relevance, and to determine appropriate DDI management strategies. P-glycoprotein $(\mathrm{P}-\mathrm{gp})$ is an efflux transporter that influences the pharmacokinetics (PK) of various compounds. Assessing transporter induction in vitro is challenging and is not always predictive of in vivo effects, and hence there is a need to consider clinical DDI studies; however, there is no clear guidance on when clinical evaluation of transporter induction is required. Furthermore, there is no proposed list of index transporter inducers to be used in clinical studies. This review evaluated DDI studies with known P-gp inducers to better understand the mechanism and site of P-gp induction, as well as the magnitude of induction effect on the exposure of P-gp substrates. Our review indicates that P-gp and cytochrome P450 (CYP450) enzymes are coregulated via the pregnane xenobiotic receptor (PXR) and the constitutive androstane receptor (CAR). The magnitude of the decrease in substrate drug exposure by P-gp induction is generally less than that of CYP3A. Most P-gp inducers reduced total bioavailability with a minor impact on renal clearance, despite known expression of P-gp at the apical membrane of the kidney proximal tubules. Rifampin is the most potent $\mathrm{P}$-gp inducer, resulting in an average reduction in substrate exposure ranging between 20 and 67\%. For other inducers, the reduction in P-gp substrate exposure ranged from 12 to $42 \%$. A lower reduction in exposure of the P-gp substrate was observed with a lower dose of the inducer and/or if the administration of the inducer and substrate was simultaneous, i.e. not staggered. These findings suggest that clinical evaluation of the impact of $\mathrm{P}$-gp inducers on the PK of investigational agents that are substrates for P-gp might be warranted only for compounds with a relatively steep exposure-efficacy relationship.
\end{abstract}

Mohamed Elmeliegy

Mohamed.Elmeliegy@pfizer.com

1 Clinical Pharmacology, Global Product Development, Pfizer Inc., 10555 Science Center Dr., San Diego, CA 92121, USA

2 Clinical Pharmacology, Global Product Development, Pfizer Inc., New York, NY, USA

\section{Key Points}

The magnitude of the decrease in substrate drug exposure by P-gp induction is generally less than that of CYP3A. Most P-gp inducers increased total bioavailability with minor impact on renal clearance.

Rifampin is the most potent P-gp inducer resulting in average reduction of substrate exposure ranging between 20 and 67\%. For other inducers, the reduction in P-gp substrate exposure ranged from 12 to $42 \%$.

A lower reduction in exposure of the P-gp substrate was observed with a lower dose of the inducer and/or if the administration of the inducer and substrate was simultaneous, i.e., not staggered. 


\section{Introduction}

\subsection{P-Glycoprotein (P-gp) Expression and its Role in Major Excretory Organs}

P-glycoprotein (P-gp), also known as multidrug resistance protein 1 (MDR1), is an efflux transporter that influences the absorption, distribution, and elimination of a variety of compounds. P-gp is expressed on apical membranes of various cells, such as those with excretory functions (e.g. hepatocytes and renal proximal tubular cells) [1], enterocytes [2], and brain capillary endothelial cells [3]. In these organs, P-gp functions to (1) limit drug absorption from the intestine to the systemic circulation with orally administered drugs; (2) limit penetration of drugs across the blood-brain barrier [3]; and (3) facilitates hepatobiliary and renal drug efflux. Therefore, the primary role of P-gp is to limit the systemic exposure of its substrates [4], and coadministration of a drug that inhibits or induces P-gp may increase or decrease, respectively, the systemic exposure of P-gp substrates [5].

\subsection{Challenges with Characterizing Transporter-Mediated Drug-Drug Interactions}

Assessing the drug-drug interaction (DDI) liability of investigational agents is an important component of drug development that involves characterization of the magnitude of the effect, the clinical relevance, and appropriate management strategies. Clinical evaluation of DDIs for an investigational agent as either a perpetrator or a victim involves the coadministration of sensitive substrates or potent modulators of particular pathways, respectively.

A clear classification of 'index' substrates/perpetrators is available for drug-metabolizing enzymes (DMEs), particularly cytochrome P450s (CYPs). For drug transporters, although there have been some initial attempts to classify substrates/perpetrators [5], there is no widely accepted classification, given that index perpetrators specific to a given transporter are largely not available. Therefore, the strategy for clinical characterization of transporter-mediated DDIs for investigational drugs that are substrates for transporters requires consideration of several factors, including the selectivity and/or sensitivity of the substrate/perpetrator for a given drug transporter, the site of action of the investigational drug (e.g. whether tissue uptake is necessary for the pharmacological effect, such as hepatic OCT1 for metformin), whether the investigational drug must be kept out of sequestered tissues to avoid toxicity, the elimination pathways of the investigational drug, likely concomitant drugs, and the safety profile of the substrate [6].

\subsection{Effect of P-gp Inducers on P-gp Substrates}

In theory, P-gp induction in the intestine, kidney, and peripheral tissues could reduce drug bioavailability, increase renal clearance, and reduce peripheral tissue distribution, respectively. The DDI potential of an investigational agent is initially evaluated in vitro; however, assessing transporter induction via in vitro methods is challenging. First, the quantitative relationship between transporter function and messenger RNA (mRNA) levels is not well understood. Levels of mRNA are highly variable and poorly correlated with protein expression [7, 8] and/or function of transporters [9]. Recent reports elucidated the role of microRNAs, short noncoding RNAs, which inhibit the translation of mRNA into proteins. These microRNAs could contribute to the discrepancy observed upon treatment with P-gp inducers, which result in significant increases in the mRNA of human encoding P-gp genes ( $A B C B 1 / M D R 1)$, yet only modest to no effect on P-gp protein levels are observed $[10,11]$. Although membrane protein expression is considered a better indicator of transporter function, the magnitude of the increase in protein expression is often a few times higher than the increase in function [12]. This discrepancy may be explained by the prominent role of post-transcriptional regulation of transporters (e.g. glycosylation) and the importance of transporter localization in determining transporter function [13-16]. Second, no validated in vitro systems are available for adequately characterizing transporter induction. Therefore, the results of in vitro studies for the evaluation of transporter induction are typically not informative for in vivo predictions.

The US FDA draft guidance suggests a staged approach to the clinical evaluation of the transporter induction potential of an investigational agent, which should be considered only if the investigational agent is shown to clinically induce CYP3A. The need and design for such clinical studies should be discussed with health authorities [6]. However, the guidance does not discuss conditions where evaluation of the impact of transporter inducers on the exposure of investigational drugs that are substrates for transporters would be needed [6]. Furthermore, it should be noted that there is no proposed list of index P-gp inducers to be used in such studies. Therefore, this review aimed to evaluate DDI studies with known P-gp inducers in an effort to provide insight into the mechanism and site of P-gp induction, as well as the magnitude of effect on pharmacokinetic (PK) exposure of P-gp substrates, to fill an important knowledge gap. Finally, high-level recommendations on the design of P-gp induction DDI studies and the clinical relevance of P-gp induction were provided based on the collective evaluation of the published P-gp induction studies. 


\section{Literature Search}

In this review, the mechanism of P-gp induction and coregulation with other drug transporters and drug metabolizing enzymes are discussed. The available literature on DDI studies with P-gp inducers coadministered with known P-gp substrates were examined to provide more insight into the magnitude of the interaction and the differential effect of P-gp induction in the intestine, renal tubules, and potentially in hepatocytes. Given the lack of validated in vitro systems for evaluating transporter induction, the P-gp inducers in scope for this review were limited to those with available clinical data. The review was also limited to sensitive P-gp substrates (i.e. those with a greater than or equal to twofold increase in exposure when coadministered with a P-gp inhibitor). For rifampin, only studies where rifampin administration was staggered relative to the P-gp substrate administration was included in this review since rifampin is a mixed inhibitor/inducer of P-gp. Coadministration of rifampin during the absorption phase of the P-gp substrate may lead to intestinal P-gp inhibition, thus confounding the assessment of potential P-gp induction [17, 18]. Although other inducers have also been shown to inhibit P-gp in vitro, the effect of staggering the inducer dosing relative to the substrate is not understood and/or has not been established; therefore, for inducers other than rifampin, studies with both staggered administration and those with concomitant administration of the P-gp inducer and substrate were included in the review. This review represents a non-systematic, narrative review of relevant articles on this topic published in databases such as the PubMed interface of MEDLINE and using keywords such as P-glycoprotein, induction, pregnane xenobiotic receptor (or PXR), constitutive androstane receptor (or CAR), or P-glycoprotein substrates, etc. [19].

\section{Key Findings}

\subsection{Mechanism of P-gp Induction}

Both the PXR and CAR are nuclear receptors that are activated by a structurally diverse spectrum of xenobiotics [20]. After activation, they bind to transcriptional binding sites for several DMEs [21, 22] and drug transporters [23], leading to increased expression of these proteins.

Binding of PXRs and/or CARs to the DR4 motif in the human $A B C B 1 / M D R 1$ promoter leads to increased transcription of P-gp [20]. The expression of various DMEs and key transporters are co-regulated via PXRs and/or CARs.

PXRs and/or CARs can regulate the expression of phase I enzymes (e.g. CYP2B6, CYP2C9, CYP2C19, CYP3A4, and CYP3A5), phase II enzymes (e.g. uridine diphosphateglucuronosyltransferase (UGT) 1A1 and and glutathione S-transferase (GST)), and drug transporters including P-gp and MRP2 [20]. Other human transporters, such as bile salt export pump (BSEP) and sodium taurocholate co-transporting polypeptide (NTCP) were also upregulated by rifampin treatment [24], suggesting possible roles of PXRs and/or CARs in regulating the expression of these transporters.

CAR and PXR expression appears to be tissue-specific, and the expression pattern of PXR and CAR in different organs could elucidate the role of P-gp induction in DDIs. Both PXR and CAR are expressed in the liver and have been established as a key regulator of CYP3A [22, 25] and CYP2C9 expression [26, 27]. PXR/CAR-mediated induction of P-gp, which is also expressed on the bile canalicular membrane, may potentially increase the biliary excretion of P-gp substrates [28, 29].

CARs have little extrahepatic expression, however PXRs are expressed in the intestine, where they are thought to play a key role in regulating the expression of $\mathrm{P}$-gp, breast cancer resistance protein (BCRP), and organic anion transporting polypeptide (OATP) 1A2 [20, 30]. Therefore, PXR-mediated $\mathrm{P}$-gp induction in the intestine may limit the absorption of P-gp substrates.

PXR expression in normal human proximal tubular kidney (NHPTK) cells was significantly lower than in human liver cancer cell lines, and HepG2 cells, which were used as a control known to express low levels of PXRs [31]. In NHPTK cells, the expression of PXR-dependent genes, including $C Y P 3 A 4, M R P 2$, and $M R P 4$, was not significantly induced by rifampin [31]; therefore, the impact of PXR activation on the induction of PXR-dependent transporters in the kidney, including P-gp, may be limited.

\subsection{P-gp Substrates}

This review was limited to sensitive P-gp substrates (fexofenadine, dabigatran etexilate, digoxin, and talinolol). Digoxin, fexofenadine, and dabigatran etexilate are listed by the FDA as clinical substrates for P-gp to be used in clinical DDI studies [32]. The PK properties of sensitive P-gp substrates in scope, together with their Biopharmaceutics Drug Distribution and Classification System (BDDCS), are discussed in the following section and summarized in Table 1 . The BDDCS replaces the permeability characteristics in the Biopharmaceutics Classification System (BCS) by route of elimination, where highly permeable BCS class 1 and 2 compounds are mainly eliminated by metabolism, while low permeability class 3 and 4 compounds are mainly eliminated by biliary or renal excretion of unchanged drug. The BDDCS enables general predictions of the role of transporters in drug disposition. BDDCS class 1 compounds are expected to have minimal transporter effects, and classes 2-4 
Table 1 Pharmacokinetic properties of P-gp substrates commonly used in clinical drug-drug interaction studies

\begin{tabular}{|c|c|c|c|c|c|c|c|}
\hline P-gp substrate & Absorption & Distribution & Elimination & Half-life & PK linearity & $\begin{array}{l}\text { BDDCS } \\
\text { classifica- } \\
\text { tion }\end{array}$ & References \\
\hline Digoxin & $\begin{array}{l}T_{\max }=1-3 \mathrm{~h} \\
F=60-80 \%\end{array}$ & $\begin{array}{l}\mathrm{Vd} \sim 6 \mathrm{~L} / \mathrm{kg} \\
\mathrm{fu} \sim 70 \%\end{array}$ & $\begin{array}{l}50-70 \% \text { renal } \\
\text { excretion }\end{array}$ & 1.5-2 days & Linear & 3 & {$[55,56]$} \\
\hline Fexofenadine & $\begin{array}{l}T_{\max }=2.6 \mathrm{~h} \\
F=\text { approximately } \\
33 \%\end{array}$ & $\begin{array}{l}\mathrm{Vd}=5.4-5.8 \mathrm{~L} / \mathrm{kg} \\
\mathrm{fu}=30-40 \%\end{array}$ & $\begin{array}{l}5 \% \text { metabolized, } \\
11 \% \text { renal excre- } \\
\text { tion, } 80 \% \text { in feces } \\
\text { (could be unab- } \\
\text { sorbed or biliary } \\
\text { excretion) }\end{array}$ & $14.4 \mathrm{~h}$ & $\begin{array}{l}\text { Linear up to a total } \\
\text { daily dose of } \\
240 \mathrm{mg}\end{array}$ & 3 & {$[57,58]$} \\
\hline $\begin{array}{l}\text { Dabigatran etex- } \\
\text { ilate }\end{array}$ & $\begin{array}{l}F=3-7 \% \\
T_{\max }=1 \mathrm{~h}\end{array}$ & $\begin{array}{c}\mathrm{Vd}=0.625- \\
0.875 \mathrm{~L} / \mathrm{kg} \\
\mathrm{fu}=65 \%\end{array}$ & $\begin{array}{l}\text { Esterase-catalyzed } \\
\text { hydrolysis to } \\
\text { dabigatran } \\
\text { (active) }\end{array}$ & $12-17 \mathrm{~h}$ & Linear $10-400 \mathrm{mg}$ & 1 & [59] \\
\hline Talinolol & $\begin{array}{l}T_{\max }=3.2 \mathrm{~h} \\
F=55 \%\end{array}$ & $\begin{array}{l}\mathrm{Vd}=3.3 \pm 0.5 \mathrm{~L} / \mathrm{kg} \\
\mathrm{fu}=45 \%\end{array}$ & $\begin{array}{l}57 \% \text { renal clear- } \\
\text { ance and } 43 \% \\
\text { non-renal clear- } \\
\text { ance (could be } \\
\text { biliary elimina- } \\
\text { tion); metabolic } \\
\text { clearance is only } \\
\text { minimal }(<1 \%)\end{array}$ & $11.9 \mathrm{~h}$ & $\begin{array}{l}\text { Dose-dependent } \\
\text { absorption (non- } \\
\text { linear) }\end{array}$ & 3 & {$[60,61]$} \\
\hline
\end{tabular}

$P$-gp P-glycoprotein, $P K$ pharmacokinetic, BDDCS Biopharmaceutics Drug Distribution and Classification System, $F$ oral bioavailability, $f u$ fraction unbound, $T_{\max }$ time to maximum systemic concentration, $V d$ volume of distribution

compounds are expected to be influenced by efflux transporters, with class 3 agents also expected to be influenced by uptake transporters [33-35].

\subsubsection{Digoxin}

Digoxin is used to treat heart failure and atrial fibrillation, and is a BDDCS class 3 compound [34]. Digoxin is an attractive probe substrate due to the following reasons: sensitivity to P-gp transport across a wide range of concentrations (i.e. large dynamic range), commercially available as radiolabeled drug, and a clinically meaningful probe substrate (narrow therapeutic index). Other transporters involved in the hepatic disposition of digoxin include OATP8 [36], sodium-dependent pathways [37], and organic solute transporter $(\mathrm{OST}) \alpha / \beta[38,39]$.

\subsubsection{Fexofenadine}

Fexofenadine is an antihistamine used to relieve allergy symptoms, and is a BDDCS class 3 compound [34]. P-gp plays a major role in the efflux of fexofenadine in the small intestine and blood-brain barrier, but only a limited role in its biliary excretion in rodents and humans [40, 41]. In mice, fexofenadine is excreted into bile primarily by multidrug resistance-associated protein (MRP) 2 (also known as ABCC2) [42], multidrug and toxin extrusion 1 (MATE1)
[43] and/or BSEP [44]. Basolateral transporters such as OATP1B3, 1A2, and 2B1, MRP3, and MRP4 are also involved in the uptake and efflux of fexofenadine [45-48].

\subsubsection{Dabigatran Etexilate}

Dabigatran etexilate is an oral prodrug that is rapidly converted to dabigatran (active), a thrombin inhibitor, resulting in very low dabigatran etexilate plasma exposure. Dabigatran etexilate, but not dabigatran, is a substrate for P-gp. Therefore, changes in dabigatran exposure reflects an alteration in P-gp function at the intestine [49]. Although administered as dabigatran etexilate, it is also important to know the mechanism of elimination for dabigatran, as it is dabigatran and not dabigatran etexilate concentrations that are assessed in plasma. Dabigatran is a substrate for the renal transporters, OCT2 [50], MATE1, and MATE2K [51]. Previous DDI studies have indicated that dabigatran etexilate (as measured by total plasma dabigatran, i.e. dabigatran and free glucuronides) is a sensitive in vivo $\mathrm{P}$-gp probe, although dabigatran etexilate is classified as BDDCS class 1, however this classification could be driven by the fact that it is a prodrug that is extensively metabolized to form the active metabolite [34]. The active metabolite, dabigatran, belongs to BDDCS class 4 [35]. Dabigatran etexilate demonstrated relatively low 
Table 2 P-gp inducers with clinical drug-drug interaction studies with P-gp substrates

\begin{tabular}{|c|c|c|c|c|c|c|}
\hline P-gp inducer & $\begin{array}{l}\text { Dosing regimen used in DDI } \\
\text { studies with P-gp substrate }\end{array}$ & $\begin{array}{l}\text { Staggered dosing } \\
\text { relative to P-gp } \\
\text { substrate }\end{array}$ & Half-life (h) & $T_{\max }(\mathrm{h})$ & Mechanism of induction & References \\
\hline Rifampin & $\begin{array}{l}600 \mathrm{mg} \text { qd or } 300 \mathrm{mg} \text { bid for } \\
6-16 \text { days }\end{array}$ & Yes & 2.5 & 2 & Strong PXR agonist & [62-68] \\
\hline Phenytoin & $0.2 \mathrm{~g}$ for 15 days & No & $23-69^{\mathrm{a}}$ & $3-12^{\mathrm{a}}$ & $\begin{array}{l}\text { Strong CAR agonist, weak } \\
\text { PXR agonist }\end{array}$ & [69-73] \\
\hline Carbamazepine & $\begin{array}{l}\text { Total daily doses of } \\
300-600 \mathrm{mg} \text {. Doses were } \\
\text { administered as } 600 \mathrm{mg} \mathrm{qd} \text {, } \\
300 \mathrm{mg} \text { bid, or } 100 \mathrm{mg} \text { tid }\end{array}$ & Yes $[74] /$ no $[75,76]$ & 35 & $2-3$ & $\begin{array}{l}\text { Strong CAR agonist, weak } \\
\text { PXR agonist }\end{array}$ & [74-81] \\
\hline St. John's wort extract & $\begin{array}{l}300 \mathrm{mg} \text { tid standardized to } \\
\text { contain } 3 \% \text { hyperforin }\end{array}$ & Yes $[82] /$ no $[65,83]$ & $4.5^{\mathrm{b}}$ & $17^{\mathrm{b}}$ & Strong PXR agonist & {$[65,82-84]$} \\
\hline Rifabutin & $300 \mathrm{mg}$ qd for 20 days & Yes & 45 & $2.5-3$ & PXR agonist & {$[75,85]$} \\
\hline Quercetin & $\begin{array}{l}500 \mathrm{mg} \text { daily to } 1.5 \mathrm{~g} \text { daily } \\
\text { (500 mg tid) for } 7-13 \text { days }\end{array}$ & Yes [86]/no [87] & 3.5 & 3 & PXR and CAR agonist & [86-89] \\
\hline Curcumin & $\begin{array}{l}600 \mathrm{mg} \text { daily ( } 200 \mathrm{mg} \text { tid) or } \\
1 \mathrm{~g} \mathrm{qd} \text { for } 6-14 \text { days }\end{array}$ & Yes [90]/no [91] & $0.5^{\mathrm{c}}$ & $\mathrm{NA}^{\mathrm{c}}$ & PXR agonist & [90-93] \\
\hline
\end{tabular}

$P$-gp P-glycoprotein, DDI drug-drug interaction, $T_{\max }$ time to maximum systemic concentration, bid twice daily, $q d$ once daily, $T I D$ three times daily, $N A$ not available, $P X R$ pregnane xenobiotic receptor, $C A R$ constitutive androstane receptor, $C O G$ curcumin-O-glucuronide

${ }^{a}$ After a single dose of phenytoin

${ }^{\mathrm{b}}$ Based on hyperforin pharmacokinetic parameters

${ }^{c}$ Based on COG, a major metabolite of curcumin. Plasma levels of parent curcumin were below the detection limit

variability together with a good safety profile, which makes it a promising P-gp probe substrate [52].

\subsubsection{Talinolol}

Talinolol is a selective $\beta 1$-adrenoceptor antagonist, and is a BDDCS class 3 compound [34]. Talinolol is a substrate for P-gp [53], OATP1A2, and OATP2B1 [54].

\subsection{P-gp Inducers}

P-gp inducers in scope for this review were those with available clinical DDI data studied using an in vivo probe P-gp substrate, including rifampin, phenytoin, curcumin, carbamazepine, genistein, St. John's wort extract, quercetin, and rifabutin. The PK properties of P-gp inducers and the potential mechanism of P-gp induction are described in Table 2.

Table 3 summarizes the design and results of clinical DDI studies in scope for this review. Only inducers associated with a $\geq 20 \%$ reduction in exposure of $\mathrm{P}$-gp substrates are discussed.

\subsubsection{Rifampin}

Several studies investigated the effect of rifampin administration on the exposure of $\mathrm{P}$-gp probe substrates, including digoxin, talinolol, fexofenadine, and dabigatran [62-64, 67, 68]. Collectively, the results of these studies showed that the mean decrease in the overall exposure of P-gp substrates ranged from 20 to $67 \%$ when coadministered with rifampin (Table 3), with impacts on dabigatran and fexofenadine exposure greater than that observed with digoxin and talinolol. These data suggest that $\mathrm{P}$-gp induction by rifampin is more evident in the enterocytes compared with the renal proximal tubules, as explained in this section.

Rifampin treatment induced intestinal $A B C B 1 / M D R I$ mRNA levels, which was associated with increased P-gp expression by 4.2 -fold and 3.5-fold, as assessed via semiquantitative methods using Western blot and immunohistochemistry, respectively [63, 64]. In these studies, the duodenal content of P-gp from gut biopsies was highly inversely correlated to digoxin and talinolol systemic exposure, demonstrating the predominant impact on intestinal P-gp [63, 64]. These results suggest that three to fourfold increases in intestinal P-gp abundances by P-gp inducers result in maximal effect in reduction of exposure of the P-gp substrate when administered orally [94], given that rifampin appears to be the strongest P-gp inducer studied to date.

Rifampin coadministration reduced the $C_{\max }$ of the orally administered P-gp substrates by $19-69.5 \%$ [63, 64, 66]. Renal clearance was unchanged with rifampin, indicating that the effect of rifampin was mainly on absorption $[63,64]$. The reduction in dabigatran area under the 


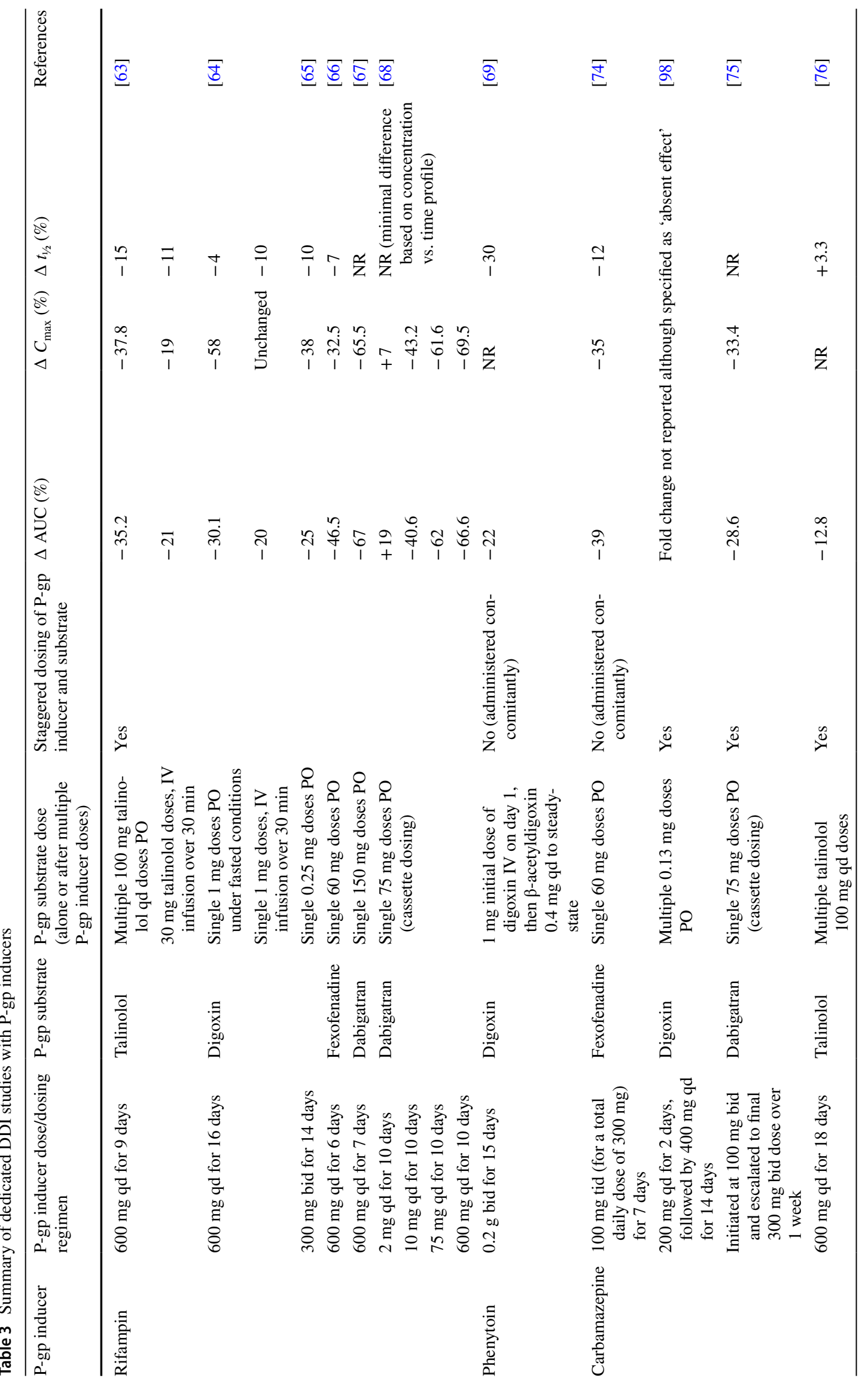




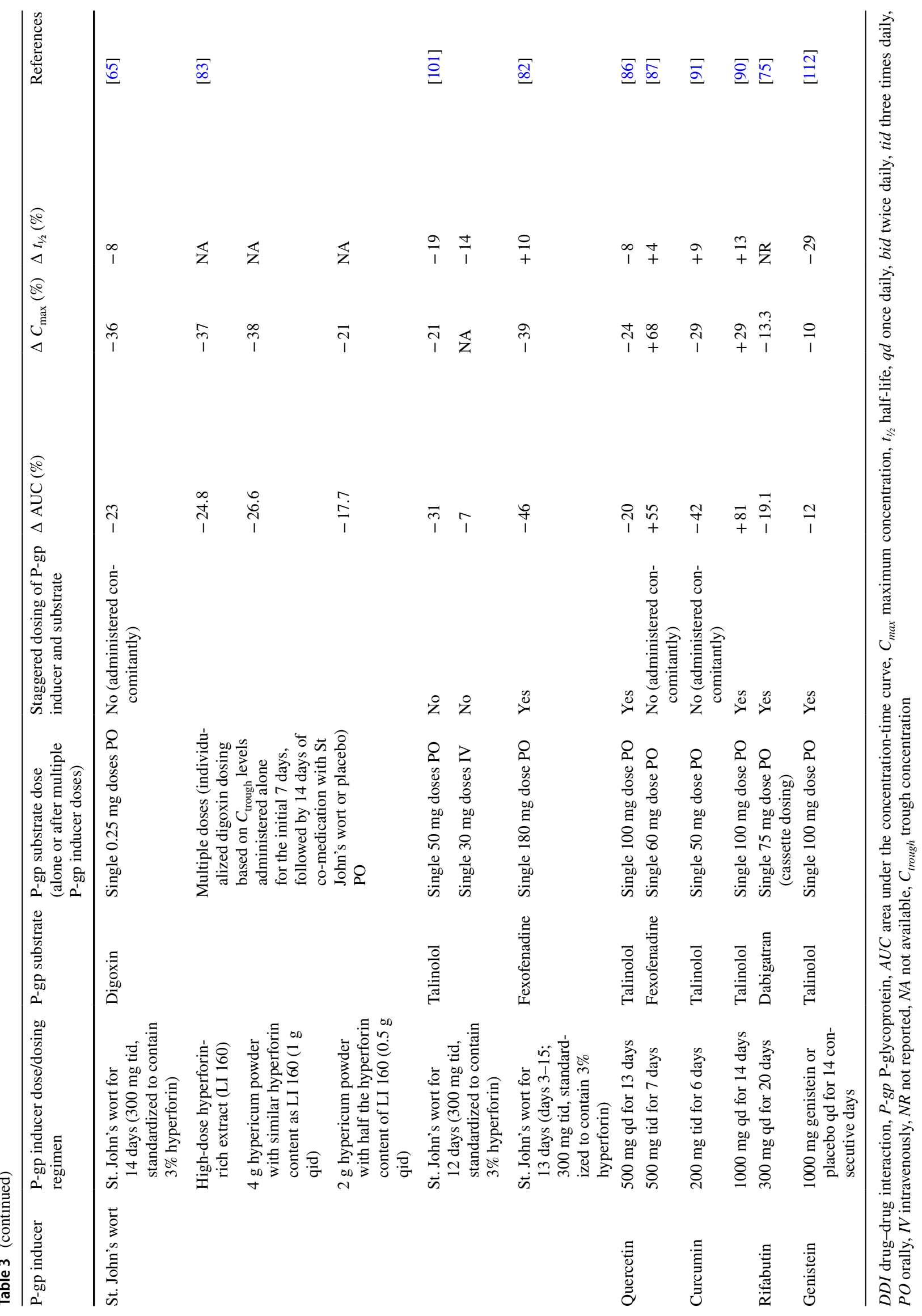


concentration-time curve from time zero to infinity (AUC $\left.{ }_{\infty}\right)$ can be explained by reduced dabigatran bioavailability, given that the reduction in $\mathrm{AUC}_{\infty}$ was accompanied with a similar approximately threefold increase in both apparent clearance $(\mathrm{CL} / \mathrm{F})$ and apparent volume of distribution during the terminal phase $(\mathrm{Vz} / \mathrm{F})$, suggesting no change in halflife $\left(t_{1 / 2}\right)$ with rifampin treatment [67]. Similarly, rifampin coadministration resulted in little to no impact on digoxin or talinolol terminal $t_{1 / 2}[63,64]$.

The rifampin/digoxin and rifampin/talinolol DDI studies also evaluated the effect of multiple doses of rifampin, administered orally, on digoxin and talinolol PK when administered intravenously [63, 64]. Both digoxin and talinolol renal clearance were relatively unchanged following intravenous administration in the presence of rifampin treatment, however the total clearance of digoxin and talinolol increased by $21 \%$ and $28 \%$, respectively, which suggests some increase in the non-renal clearance route of digoxin and talinolol $\left(\mathrm{CL}_{\mathrm{nr}}=\mathrm{CL}_{\text {tot }}-\mathrm{CL}_{\text {renal }}\right)[60,63,64,95]$. A similar finding was observed for phenytoin/digoxin interaction [69]. The increase in non-renal clearance of some P-gp substrates with rifampin coadministration could be due to the induction of P-gp in hepatocytes, leading to increased biliary elimination, or due to the induction of hepatic uptake transporters, e.g. OATP, or both. The potential for OATP by rifampin is discussed later.

Another study by Lutz et al. investigated the effect of escalating doses of rifampin on P-gp induction, as assessed via dabigatran exposure. Rifampin decreased dabigatran exposure in a dose-dependent manner. When coadministered with multiple doses of rifampin 2, 10, 75, and $600 \mathrm{mg}$ for 10 days, the dabigatran $\mathrm{AUC}_{\infty}$ was $20 \%$ higher, $40.6 \%$ lower, $62 \%$ lower, and $66.6 \%$ lower, respectively, compared with dabigatran administered alone. The significance of the results of this study will be further discussed later [68].

Collectively, the findings of these studies suggest that the effect of rifampin on P-gp substrate exposure can be explained, predominantly due to P-gp induction in the intestine with minimal impact on renal P-gp.

\subsubsection{Phenytoin}

Phenytoin coadministration resulted in a $22 \%$ lower digoxin AUC in the absence of an effect on renal clearance $(136 \pm 28.3 \mathrm{~mL} / \mathrm{min}$ and $120 \pm 52 \mathrm{~mL} / \mathrm{min}$ for digoxin alone and digoxin with phenytoin, respectively), suggesting minimal/no impact on renal P-gp by phenytoin. Phenytoin increased digoxin total systemic clearance by $27 \%$, indicating an increase in non-renal clearance, potentially via induction of P-gp in hepatocytes, leading to increased biliary elimination of digoxin, which can account for approximately $10-30 \%$ of total digoxin elimination [95-97]. This finding is similar to that observed in the rifampin/digoxin interaction
[64] and suggests P-gp induction in the liver and small intestine, but not in the kidney. Consistent with the increase in the total systemic clearance of digoxin with phenytoin, mean digoxin terminal $t_{1 / 2}$ was reduced by $30 \%$ (from $33.9 \mathrm{~h}$ for digoxin alone to $23.7 \mathrm{~h}$ for digoxin when coadministered with phenytoin) [69].

\subsubsection{Carbamazepine}

Several studies evaluated the effect of the antiepileptic agent carbamazepine on the exposure of the P-gp substrates fexofenadine, talinolol, dabigatran etexilate, and digoxin [74-76, 98]. Yamada et al. investigated the effect of carbamazepine, a known inducer of several CYP enzymes [81], on the PK of fexofenadine [74]. Carbamazepine decreased fexofenadine AUC and $C_{\max }$ by $39 \%$ and $35 \%$, respectively. Similar to findings with rifampin/digoxin and phenytoin/ digoxin interactions, the change in fexofenadine renal clearance was minor. A minimal change in fexofenadine elimination $t_{1 / 2}$ was observed with carbamazepine. Of note, carbamazepine led to an increase in fexofenadine CL/F and apparent volume of distribution $(\mathrm{Vd} / \mathrm{F})$ with relatively similar magnitude (CL/F and Vd/F increased by $84 \%$ and $61 \%$, respectively) and minimal/no change in fexofenadine $t_{1 / 2}(3.4 \pm 0.7$ and $3.0 \pm 0.9 \mathrm{~h}$ for fexofenadine alone and fexofenadine with carbamazepine, respectively) [74]. This suggests that the carbamazepine induction effect seems to be mainly driven by reduced bioavailability, via P-gp and/or MRP2 induction, and therefore largely appears to be a localized effect to the gut.

Lutz et al. studied the effect of multiple carbamazepine doses on dabigatran exposure after single-dose administration of the intestinal P-gp substrate dabigatran etexilate (prodrug). The reduction in dabigatran exposure with carbamazepine was $28.6 \%$ and $33.4 \%$ for $\mathrm{AUC}_{\infty}$ and $C_{\max }$, respectively [75]. The reduction in the exposure of dabigatran, an intestinal P-gp probe substrate, suggests increased intestinal P-gp expression and/or functional activity that is not consistent with the findings from Brueck et al., which suggest the lack of an increase in intestinal P-gp protein levels [10].

Multiple-dose administration of oral carbamazepine did not change talinolol AUC, total or renal clearance, volume of distribution, or $t_{1 / 2}$ after intravenous administration of talinolol. Talinolol steady-state PK were also assessed when orally administered alone and with multiple doses of carbamazepine. Carbamazepine reduced talinolol steadystate exposure $\left(\mathrm{AUC}_{\tau}\right)$ by $12.8 \%$, which was associated with a $14.3 \%$ decrease in bioavailability and no change in $t_{1 / 2}$. These data suggest that the P-gp induction effect by carbamazepine was predominantly in the gut, rather than in the kidney or liver [76]. While carbamazepine increased talinolol renal clearance when administered orally, this 
effect was not observed when talinolol was administered via the intravenous route, which suggests that the effect of carbamazepine on renal P-gp is variable since the effect of carbamazepine on renal clearance should be independent of the route of administration of the probe substrate [76].

Another study showed no effect of carbamazepine on digoxin exposure [98]. In general, the magnitude of reduction of P-gp substrate exposures in these four studies ranged from no effect to $39 \%$ (Table 3) [74-76, 98].

While the majority of studies discussed suggest a localized carbamazepine effect on intestinal P-gp, this is not consistent with data showing that carbamazepine treatment did not increase intestinal P-gp protein abundance in duodenal biopsy samples from healthy volunteers despite increased intestinal MDR1 mRNA [10, 76]. Brueck et al. [10] suggested that carbamazepine upregulates renal P-gp via CAR induction, given that carbamazepine is a CAR activator and that carbamazepine achieves systemic exposures higher than concentrations needed for enzyme induction in vitro [81]. However, the mRNA expression of CAR in the kidney is relatively low $[20,99]$. Furthermore, the systemic concentrations required to induce $\mathrm{P}$-gp are likely higher than those needed to induce CYP enzymes, which is supported by the lack of $A B C B 1 / M D R 1$ gene induction in the livers of patients treated with carbamazepine $[75,100]$. Finally, the totality of evidence from available carbamazepine studies with probe P-gp substrates does not support renal P-gp induction by carbamazepine [74-76, 98].

There are a couple of potential explanations for the lower exposure of P-gp substrates without a significant impact on renal clearance, including (1) increased intestinal P-gp functional activity without a detectable increase in protein levels; and (2) increased biliary excretion of P-gp substrates via the induction of MRP2 (the main transporter in fexofenadine biliary excretion of fexofenadine) and/or increased hepatic uptake via OATP induction [42].

\subsubsection{St. John's Wort}

St. John's wort treatment containing similar hyperforin content (approximately $300 \mathrm{mg}$ ) was associated with a $46 \%$, $31 \%$, and approximately $25 \%$ lower AUC of the P-gp substrates fexofenadine, talinolol, and digoxin, respectively, after oral administration of these P-gp substrates $[65,82$, $83,101]$. A St. John's wort preparation with half the hyperforin content resulted in a slightly lower reduction in digoxin exposure (18\% and $21 \%$ lower AUC and $C_{\max }$, respectively) [83]. St. John's wort treatment did not markedly reduce the terminal $t_{1 / 2}$ for either fexofenadine [82], talinolol [101], or digoxin [65]. Interestingly, the fexofenadine DDI study staggered St. John's wort treatment (resulting in a $46 \%$ lower AUC), while the talinolol study and both digoxin studies did not (resulting in a $31 \%$ and approximately $25 \%$ lower AUC, respectively). This may suggest that concomitant administration of St. John's wort with P-gp substrates may be associated with a lower induction effect, although this cross-study comparison is complicated by the use of different P-gp substrates, as well as the highly variable induction effect of St. John's wort even with the similar hyperforin content used in both studies [102]. Consistent with findings from other P-gp inducers, the lack of effect on fexofenadine, talinolol, and digoxin terminal $t_{1 / 2}$ and the reduction of overall exposure suggest that the induction effect of St. John's wort is predominantly on intestinal P-gp [65, 82, 101]. This is consistent with the increase in MDR1 mRNA as well as P-gp protein levels in duodenal biopsies of healthy subjects [101].

\subsubsection{Quercetin}

The effect of quercetin on P-gp seems to be dual in nature. On the one hand, the study by Wang et al. demonstrated a $20 \%$ reduction in talinolol exposure when coadministered with quercetin, which suggests P-gp induction by quercetin [86]. Furthermore, quercetin decreased the exposure of cyclosporine by $43.3 \%$ in rats [103]. However, cyclosporine is also metabolized via CYP3A (also induced by quercetin), thus the relative contribution of $\mathrm{P}$-gp induction to the observed decrease in cyclosporine exposure cannot be determined. On the other hand, some studies showed that quercetin could inhibit P-gp. Quercetin increased the exposure of digoxin in pigs, with a 2.7 -fold higher AUC when digoxin was administered with quercetin compared with digoxin alone [104]. Additionally, quercetin was shown to increase fexofenadine exposure in healthy human subjects by $55 \%$ [87].

Given that P-gp and CYP3A4 are co-regulated via PXRs, the nature of the modulatory effect of quercetin on P-gp (inhibition vs. induction) could be inferred from its effect on CYP3A. Consistent with data from in vivo studies with quercetin and P-gp substrates, some in vitro studies investigating the modulatory effect of quercetin on CYP3A showed quercetin as an inhibitor of CYP3A4 [105, 106], while other reports showed CYP3A4 induction by quercetin [107].

The discrepancy in studies showing P-gp inhibition versus induction with quercetin might be explained by the different staggering conditions in studies where quercetin dosing was staggered with respect to talinolol [86], but administered concomitantly with digoxin in pigs [104] and with fexofenadine [87] (Table 2). Another alternative explanation could be the concentration-dependent effect of quercetin on P-gp. In vitro, high concentrations of quercetin $(50$ or $100 \mu \mathrm{M})$ inhibited P-gp, while low concentrations of quercetin $(10 \mu \mathrm{M})$ were shown to induce P-gp [108, 109]. Consistent with this hypothesis, the quercetin-fexofenadine DDI study in healthy subjects, which showed an increase in fexofenadine exposure, used a high dose of $500 \mathrm{mg}$ three 
times daily (total dose of $1500 \mathrm{mg} /$ day) for 7 days [87]. A lower daily dose of $500 \mathrm{mg}$ once daily for 13 days was used in the quercetin-talinolol DDI study, which showed decreased talinolol exposure consistent with P-gp induction [86]. Note that a similar explanation could be made regarding the discrepant results for curcumin, as discussed below. In the quercetin-talinolol DDI study, which used a lower daily dose of $500 \mathrm{mg}$ once daily, the $20 \%$ lower $\mathrm{AUC}_{\infty}$ was associated with a minimal decrease in the terminal $t_{1 / 2}$ (i.e. $8 \%$ shorter). In this study, renal clearance was not calculated; however, given that renal clearance represents a major elimination pathway for talinolol, and given the minimal impact on $t_{1 / 2}$, it is expected that the effect of quercetin on talinolol renal elimination is minimal.

\subsubsection{Curcumin}

Two studies investigated the effect of curcumin on the systemic exposure of talinolol. In one study, the presence of curcumin was associated with a decrease in the rate $(29 \%$ lower $\left.C_{\max }\right)$ and extent (42\% lower AUC) of talinolol absorption. In vitro, curcumin and its metabolite tetrahydrocurcumin resulted in significant concentration-dependent upregulation of mRNA of the P-gp encoding gene $A B C B 1 /$ $M D R 1$ in Caco-2 cells [91]. In agreement with the notion that P-gp induction seems to be only localized to the gut, in the curcumin/talinolol study curcumin seemed to affect only talinolol oral bioavailability (F) and not its systemic clearance since the increase in $\mathrm{CL} / \mathrm{F}$ and $\mathrm{Vd} / \mathrm{F}$ was similar [91].

In another study, coadministration of curcumin with talinolol was shown to increase talinolol $C_{\max }$ and AUC by $20 \%$ and $81 \%$, respectively [90]. Therefore, like quercetin, conflicting reports exist on the modulatory effect of curcumin on P-gp. Staggering of the curcumin dosing with talinolol in these two studies does not explain the discrepant results as talinolol exposure was increased with staggered curcumin dosing. The major difference that could explain the discordant results in the two studies was the curcumin dose. A lower daily dose was administered in a fractionated manner in the study where curcumin lowered talinolol exposure (200 mg three times daily, total daily dose $600 \mathrm{mg}$ for 6 days) [91], while in the study where curcumin increased talinolol exposure [90], curcumin was administered as a total dose of $1 \mathrm{~g}$ once daily for 14 days (Table 3). It could be postulated that, similar to quercetin, a higher curcumin dose in the gut is needed to inhibit P-gp, while lower curcumin doses can induce P-gp activity. In vitro, curcumin at relatively high concentrations of 30-60 $\mu \mathrm{M}$ were shown to inhibit P-gpmediated digoxin transport in L-MDR1 and Caco-2 cells [110]. Further exploration into the concentration-dependent modulatory effect of curcumin on P-gp might be warranted.

In fact, a study investigating the effect of curcumin as a BCRP inhibitor showed a 3.2-fold increase in the exposure of the BCRP substrate sulfasalazine when curcumin was administered at a high dose of $2 \mathrm{~g} 30 \mathrm{~min}$ prior to sulfasalazine administration [111]. This suggests that transporter inhibition by curcumin at the gut level might only be achievable at relatively high doses. Interestingly, curcumin plasma concentrations were lower than the limit of quantification of the assay $(1 \mathrm{ng} / \mathrm{mL})$. Therefore, with such low systemic exposures of curcumin, the modulatory effect of curcumin on transporters (P-gp or BCRP), even at the high dose of $2 \mathrm{~g}$, will be limited only to the gut and no effect would be expected in the kidney or liver.

\subsection{Induction of Other Transporters [Organic Anion Transporting Polypeptide (OATP) and Breast Cancer Resistance Protein (BCRP)]}

While the main focus of our review was P-gp induction, we also noted that the exposure of pravastatin, an OATP substrate, was reduced by a similar extent as that for dabigatran etexilate when coadministered with rifampin $(-59 \%$ vs. $-62 \%$ for pravastatin vs. dabigatran etexilate at the $75 \mathrm{mg}$ dose, and $-53 \%$ vs. $-67 \%$ for pravastatin vs. dabigatran etexilate at the $600 \mathrm{mg}$ dose) [68]. However, it is important to note that pravastatin is also a substrate for MRP2 $[113,114]$ and induction of intestinal MRP2 by rifampin [115] could also explain, at least partially, the reduction in pravastatin exposure. Although OATP induction by rifampin cannot be excluded, in vitro data are not supportive of this observation. Therefore, further understanding of the clinical relevance of OATP induction is warranted [116].

The decrease in the exposure of the BCRP/OATP probe substrate rosuvastatin was similar to that for pravastatin (63\% vs. 59\% lower AUC for rosuvastatin and pravastatin). Studies showed that the most frequent polymorphism in the gene encoding BCRP, i.e. $421 \mathrm{CA} A B C G 2$, resulted in an approximately $80 \%$ increase in rosuvastatin overall exposure compared with 421 AA $A B C G 2$ [117], but no such effect was observed for pravastatin [118]. This suggests that BCRP-mediated intestinal transport of pravastatin may not be as clinically relevant as for rosuvastatin. With this assumption, the similar fraction transported by OATP for both pravastatin and rosuvastatin, and the similar decrease in the exposure of pravastatin and rosuvastatin, suggest that BCRP is not inducible [68]. Data from Brueck et al. suggest that mRNA expression of the gene encoding BCRP, $A B C G 2$, was increased with carbamazepine treatment but not rifampin [10]; however, on the protein level, neither carbamazepine nor rifampin increased BCRP protein abundance in duodenal biopsies.

Overall, the available data from the lack of increase in intestinal BCRP protein levels with rifampin or carbamazepine, as well as the results showing a similar decrease in pravastatin and rosuvastatin exposure with rifampin, suggest 
that BCRP induction is unlikely to be clinically relevant [10]. Other inducible transporters are out of scope for this review.

\section{Interpretation and Practical Implications of Key Findings}

Several compounds are shown to be substrates for P-gp in vitro; however, clinical studies investigating the effect of P-gp modulation have not been conducted in many cases. This is reflected in the labeling recommendations of several compounds, acknowledging that the drug is a substrate for transporters based on in vitro data and that the impact of transporter modulation on the PK exposure has not been studied. This could represent a significant knowledge gap given that P-gp inhibition or induction may increase or decrease, respectively, the systemic exposure of these compounds. P-gp inhibitors can increase systemic exposure of P-gp substrates either via inhibition of intestinal P-gp (i.e. increasing bioavailability) [119] or inhibition of renal P-gp (i.e. reducing renal clearance) [120-122]. This could be especially important for P-gp substrates that are predominantly renally eliminated and with a relatively narrow therapeutic index. The effect of P-gp inhibition is out of scope of this review and the reader is directed to other reports on the effect of P-gp inhibition [4, 5]. The clinical relevance of P-gp inducers is discussed in the following section.

Despite the co-regulation of P-gp and CYP450 enzymes via PXRs and CARs, and in contrast to established classification for perpetrators of CYP enzymes, no clear classification is available for inducers of drug transporters. However, the available data from clinical DDI studies, as summarized in this review, show that the magnitude of the decrease in substrate drug exposure by P-gp induction is generally one category lower than that of CYP3A induction using the same categorization for both enzymes (strong, moderate, or weak inducer, decreasing the AUC of a sensitive substrate by $\geq 80 \%, 50$ to $80 \%$, and 20 to $50 \%$, respectively). For example, rifampin, carbamazepine, and phenytoin showed a greater reduction in the exposure of midazolam (a sensitive CYP3A4 substrate, approximately 90-95\% lower exposure) compared with dabigatran etexilate (considered a sensitive substrate for intestinal P-gp, $<67 \%$ lower exposure) $[67,68,75,123]$. Carbamazepine reduced midazolam exposure by $79 \%$ (i.e. moderate CYP3A4 inducer) and reduced dabigatran exposure by only $28.6 \%$ (i.e. weak inducer) [75]. Rifabutin reduced midazolam exposure by $69 \%$ (i.e. moderate CYP3A inducer), while the reduction in dabigatran exposure with rifabutin was $19.1 \%$, i.e. weak inducer) [75]. A similar observation could be made using cross-study comparisons for PXR inducers when tested with CYP3A versus P-gp probe substrates. For example, carbamazepine decreased the mean exposure of the CYP3A4 probe substrate simvastatin by $75 \%$ [124], compared with a $39 \%$ decrease in fexofenadine exposure [74]. Similarly, the extent of induction of oral clearance by St. John's wort was more for midazolam compared with fexofenadine [82]. In general, the magnitude, and hence the clinical relevance, of $\mathrm{P}$-gp induction is expected to be less than CYP3A4 induction for any given PXR/CAR inducer $[68,75]$.

Comparison of the magnitude of P-gp induction with the inducers summarized in this review show that the expected reduction in P-gp substrate exposure ranges from 20 to $67 \%$. Rifampin appears to be the strongest P-gp inducer studied to date, possibly because of its high intestinal levels relative to PXR-activating concentrations. For rifampin studies under similar rifampin dosing regimens, dabigatran etexilate and fexofenadine appeared to be more sensitive P-gp substrates as the extent of exposure reduction was more evident compared with that with talinolol or digoxin.

Apart from rifampin studies with fexofenadine and dabigatran etexilate, both the FDA and European Medicines Agency (EMA) recommended P-gp probe drugs; the range of the average reduction in P-gp substrate exposures across studies was $12-42 \%$. Furthermore, the majority of P-gp inducers mainly reduced bioavailability, but with limited impact on the elimination of the respective P-gp substrates (Table 3). This suggests that P-gp induction occurs primarily in the intestine and that extra-intestinal P-gp (renal or hepatic) is potentially less sensitive to induction. One explanation for the minimal change in renal clearance of P-gp substrates when coadministered with a P-gp inducer could be the low PXR expression in kidney tubules, as indicated by mRNA expression [31]. Interestingly, CYP3A4 expression was not significantly induced following rifampin treatment in kidney cell lines, which may indicate that rifampin induces gene expression in a tissue-specific manner depending on the levels of PXRs in specific tissues [31]. Another explanation could be that some inducers (e.g. rifampin) achieve sustainable intestinal concentrations sufficient for P-gp induction, possibly because they undergo enterohepatic recirculation, while systemic concentrations of these inducers are likely insufficient for PXR/CAR induction in the kidney [10, 62]. Given that P-gp induction is primarily in the intestine, the impact on P-gp substrates could be primarily evident on days where the P-gp inducer and P-gp substrate are coadministered. This is because P-gp activity is expected to be restored to baseline within approximately 1 week after discontinuation of the inducer, given the relatively fast P-gp turnover rate of 5-17 h $[18,67,125]$.

From a clinical perspective, for P-gp inducers that are used for only a short duration, a transient reduction of $20-40 \%$ in exposure might not affect the clinical profile (efficacy and/or safety) for the compound unless this is supported by a steep exposure-efficacy relationship (e.g. 
for compounds with a narrow therapeutic index, such as digoxin). Another potential approach to mitigate the effect of P-gp induction on substrates is to consider simultaneous coadministration of the P-gp inducer and substrate if the $\mathrm{P}$-gp inducer is also an inhibitor of P-gp (e.g. rifampin). Simultaneous administration of rifampin and digoxin to evaluate the net effect of P-gp induction and inhibition increased digoxin AUC by $25 \%$, while staggering rifampin dosing to evaluate P-gp induction only led to a $19 \%$ lower digoxin AUC as rifampicin is a mixed inducer/inhibitor of P-gp [18]. Therefore, administration of mixed P-gp inducers/ inhibitors, such as rifampin, during the absorption phase of the P-gp substrate may result in transient P-gp inhibition, which could potentially minimize the reduction in the overall exposure, or even result in no net effect or even a minimal increase in P-gp substrate exposure [17, 126].

An important point to highlight is that BDCCS class 1 drugs are unlikely to be affected by P-gp induction, given that transporters (e.g. P-gp) are not expected to play a major role in limiting their disposition [33]. The impact of transporters on the bioavailability of compounds in other BDCCS classes could be challenging to predict [33].

Our review indicates that the magnitude of the exposure reduction of P-gp substrates when St. John's wort was administered concomitantly with the P-gp substrate was less compared with when staggered, although this crossstudy comparison is complicated by the use of different P-gp substrates. On the other hand, carbamazepine treatment reduced the exposure of the P-gp substrate regardless of the staggering conditions, and curcumin reduced talinolol exposure despite concomitant administration. Therefore, reduced exposure of P-gp substrates might be more evident with staggered dosing (e.g. rifampin, St. John's wort, and quercetin), while other inducers may show decreased exposure of the substrate irrespective of dose staggering (e.g. carbamazepine).

The design of dedicated DDI studies with inducers, if needed, should be fit for purpose. For example, to assess the worst-case DDI scenario, staggering of the inducer and substrate dosing should be considered to avoid a potential confounding effect of transient P-gp inhibition. Additionally, rifampicin $600 \mathrm{mg}$ once daily for at least 7 days should be considered as the index P-gp inducer. However, to test likely real-world dosing conditions that may decrease the impact, or even completely mitigate the effect, of the P-gp inducer on substrate exposure, simultaneous coadministration might be considered. The need, design, and timing of such DDI studies should be determined based on careful understanding of the drug PK properties, elimination routes, transporters involved, and the exposure-response relationship.

Physiologically based PK (PBPK) modeling represents a bottom-up approach for evaluating the effect of intrinsic and extrinsic factors on drug exposure [127]. These models have been increasingly used to assess CYP450 enzymemediated DDIs to derive dosing recommendations in lieu of dedicated clinical studies $[6,128]$. In recent years, examples on the use of PBPK for substrates of OATP, renal transporters, and P-gp have been described [94, 128]. For example, talinolol PK were described using a PBPK model that incorporated the saturable kinetics of P-gp in the intestine and adequately described the increased oral bioavailability with higher talinolol doses [129]. However, further research and validation of these models is needed. The challenges with PBPK predictions of transportermediated DDIs arise from the difficulty in clinical translation of in vitro data and the uncertainty in predicting major processes governing the transporter function. This includes uncertainty in transporter transcription, expression, tissue distribution, cellular localization, and the variability of data from in vitro assays. Furthermore, the poor correlation between the transporter transcription, expression, and functional activity in response to inducers further complicates the ability of PBPK models to adequately predict transporter induction-mediated DDIs [128].

The findings from this review suggest that dedicated DDI studies to characterize the impact of P-gp inducers on the exposure of an investigational drug that is a substrate for P-gp may only be warranted for P-gp substrates with a steep exposure-efficacy relationship. A cautionary statement may be added to the drug label of the P-gp substrate to highlight the lack of clinical DDI studies with $\mathrm{P}$-gp inducers. If the investigational agent is a substrate for CYP enzymes and P-gp, which is common, a significant reduction in exposure with strong PXR/CAR activators is expected, and therefore investigating or restricting the use of strong inducers with such investigational agents should be considered.

\section{Compliance with Ethical Standards}

Conflict of interest Mohamed Elmeliegy, Manoli Vourvahis, Cen Guo, and Diane D. Wang are employees of Pfizer and receive stock and stock options as part of their employment.

Open Access This article is licensed under a Creative Commons Attribution-NonCommercial 4.0 International License, which permits any non-commercial use, sharing, adaptation, distribution and reproduction in any medium or format, as long as you give appropriate credit to the original author(s) and the source, provide a link to the Creative Commons licence, and indicate if changes were made. The images or other third party material in this article are included in the article's Creative Commons licence, unless indicated otherwise in a credit line to the material. If material is not included in the article's Creative Commons licence and your intended use is not permitted by statutory regulation or exceeds the permitted use, you will need to obtain permission directly from the copyright holder.To view a copy of this licence, visit http://creativecommons.org/licenses/by-nc/4.0/. 


\section{References}

1. Tanigawara Y. Role of P-glycoprotein in drug disposition. Ther Drug Monit. 2000;22(1):137-40.

2. Fromm MF. P-glycoprotein: a defense mechanism limiting oral bioavailability and CNS accumulation of drugs. Int J Clin Pharmacol Ther. 2000;38(2):69-74.

3. Fromm MF. Importance of P-glycoprotein at blood-tissue barriers. Trends Pharmacol Sci. 2004;25(8):423-9.

4. Lin JH, Yamazaki M. Role of P-glycoprotein in pharmacokinetics: clinical implications. Clin Pharmacokinet. 2003;42(1):59-98.

5. Lund M, Petersen TS, Dalhoff KP. Clinical implications of P-glycoprotein modulation in drug-drug interactions. Drugs. 2017;77(8):859-83.

6. FDA, Clinical Drug Interaction Studies-Study Design, Data Analysis, and Clinical Implications-Guidance for Industry; 2017.

7. Ahlin G, et al. Endogenous gene and protein expression of drugtransporting proteins in cell lines routinely used in drug discovery programs. Drug Metab Dispos. 2009;37(12):2275-83.

8. Thompson CG, et al. Multimodal analysis of drug transporter expression in gastrointestinal tissue. AIDS. 2017;31(12):1669-78.

9. Ohtsuki S, et al. Simultaneous absolute protein quantification of transporters, cytochromes P450, and UDP-glucuronosyltransferases as a novel approach for the characterization of individual human liver: comparison with mRNA levels and activities. Drug Metab Dispos. 2012;40(1):83-92.

10. Brueck $\mathrm{S}$, et al. Transcriptional and post-transcriptional regulation of duodenal P-glycoprotein and MRP2 in healthy human subjects after chronic treatment with rifampin and carbamazepine. Mol Pharm. 2019;16(9):3823-30.

11. Bruckmueller $\mathrm{H}$, et al. Clinically relevant multidrug transporters are regulated by microRNAs along the human intestine. Mol Pharm. 2017;14(7):2245-53.

12. Guo C, et al. Farnesoid X receptor agonists obeticholic acid and chenodeoxycholic acid increase bile acid efflux in sandwich-cultured human hepatocytes: functional evidence and mechanisms. J Pharmacol Exp Ther. 2018;365(2):413-21.

13. Gu X, Manautou JE. Regulation of hepatic ABCC transporters by xenobiotics and in disease states. Drug Metab Rev. 2010;42(3):482-538.

14. Schonhoff CM, Webster CR, Anwer MS. Taurolithocholateinduced MRP2 retrieval involves MARCKS phosphorylation by protein kinase $\mathrm{C}$ in HUH-NTCP Cells. Hepatology. 2013;58(1):284-92.

15. Chandra $P$, et al. Modulation of hepatic canalicular or basolateral transport proteins alters hepatobiliary disposition of a model organic anion in the isolated perfused rat liver. Drug Metab Dispos. 2005;33(8):1238-43.

16. Zhang $\mathrm{P}$, et al. Role of glycosylation in trafficking of Mrp2 in sandwich-cultured rat hepatocytes. Mol Pharmacol. 2005;67(4):1334-41.

17. Kirby BJ, et al. Complex drug interactions of the HIV protease inhibitors 3: effect of simultaneous or staggered dosing of digoxin and ritonavir, nelfinavir, rifampin, or bupropion. Drug Metab Dispos. 2012;40(3):610-6.

18. Reitman ML, et al. Rifampin's acute inhibitory and chronic inductive drug interactions: experimental and model-based approaches to drug-drug interaction trial design. Clin Pharmacol Ther. 2011;89(2):234-42.

19. Collins JA, Fauser BC. Balancing the strengths of systematic and narrative reviews. Hum Reprod Update. 2005;11(2):103-4.
20. Wang YM, et al. Role of CAR and PXR in xenobiotic sensing and metabolism. Expert Opin Drug Metab Toxicol. 2012;8(7):803-17.

21. Kliewer SA, et al. An orphan nuclear receptor activated by pregnanes defines a novel steroid signaling pathway. Cell. 1998;92(1):73-82.

22. Goodwin B, Hodgson E, Liddle C. The orphan human pregnane $\mathrm{X}$ receptor mediates the transcriptional activation of CYP3A4 by rifampicin through a distal enhancer module. Mol Pharmacol. 1999;56(6):1329-39.

23. Geick A, Eichelbaum M, Burk O. Nuclear receptor response elements mediate induction of intestinal MDR1 by rifampin. J Biol Chem. 2001;276(18):14581-7.

24. Olinga $\mathrm{P}$, et al. Coordinated induction of drug transporters and phase I and II metabolism in human liver slices. Eur J Pharm Sci. 2008;33(4-5):380-9.

25. Lehmann JM, et al. The human orphan nuclear receptor PXR is activated by compounds that regulate CYP3A4 gene expression and cause drug interactions. J Clin Investig. 1998;102(5):1016-23.

26. Ferguson SS, et al. Regulation of human CYP2C9 by the constitutive androstane receptor: discovery of a new distal binding site. Mol Pharmacol. 2002;62(3):737-46.

27. Chen $Y$, et al. Induction of human CYP2C9 by rifampicin, hyperforin, and phenobarbital is mediated by the pregnane $\mathrm{X}$ receptor. J Pharmacol Exp Ther. 2004;308(2):495-501.

28. Liu H, Sahi J. Role of hepatic drug transporters in drug development. J Clin Pharmacol. 2016;56(Suppl 7):S11-22.

29. Patel M, Taskar KS, Zamek-Gliszczynski MJ. Importance of hepatic transporters in clinical disposition of drugs and their metabolites. J Clin Pharmacol. 2016;56(Suppl 7):S23-39.

30. Meyer zu Schwabedissen HE, et al. Interplay between the nuclear receptor pregnane $\mathrm{X}$ receptor and the uptake transporter organic anion transporter polypeptide $1 \mathrm{~A} 2$ selectively enhances estrogen effects in breast cancer. Cancer Res. 2008;68(22):9338-47.

31. Benson EA, et al. Rifampin regulation of drug transporters gene expression and the association of MicroRNAs in human hepatocytes. Front Pharmacol. 2016;7:111.

32. FDA, Drug development and drug interactions: table of substrates, inhibitors and inducers; 2017.

33. Shugarts S, Benet LZ. The role of transporters in the pharmacokinetics of orally administered drugs. Pharm Res. 2009;26(9):2039-54.

34. Benet LZ, Broccatelli F, Oprea TI. BDDCS applied to over 900 drugs. AAPS J. 2011;13(4):519-47.

35. Hosey CM, Chan R, Benet LZ. BDDCS predictions, self-correcting aspects of BDDCS assignments, BDDCS assignment corrections, and classification for more than 175 additional drugs. AAPS J. 2016;18(1):251-60.

36. Kullak-Ublick GA, et al. Organic anion-transporting polypeptide B (OATP-B) and its functional comparison with three other OATPs of human liver. Gastroenterology. 2001;120(2):525-33.

37. Taub ME, et al. Digoxin is not a substrate for organic aniontransporting polypeptide transporters OATP1A2, OATP1B1, OATP1B3, and OATP2B1 but is a substrate for a sodiumdependent transporter expressed in HEK293 cells. Drug Metab Dispos. 2011;39(11):2093-102.

38. Seward DJ, et al. Functional complementation between a novel mammalian polygenic transport complex and an evolutionarily ancient organic solute transporter, OSTalpha-OSTbeta. J Biol Chem. 2003;278(30):27473-82.

39. Malinen MM, et al. Organic solute transporter OSTalpha/beta is overexpressed in nonalcoholic steatohepatitis and modulated by drugs associated with liver injury. Am J Physiol Gastrointest Liver Physiol. 2018;314(5):G597-G609. 
40. Tahara H, et al. P-glycoprotein plays a major role in the efflux of fexofenadine in the small intestine and blood-brain barrier, but only a limited role in its biliary excretion. Drug Metab Dispos. 2005;33(7):963-8.

41. Swift B, Tian X, Brouwer KL. Integration of preclinical and clinical data with pharmacokinetic modeling and simulation to evaluate fexofenadine as a probe for hepatobiliary transport function. Pharm Res. 2009;26(8):1942-51.

42. Tian X, et al. Multidrug resistance-associated protein 2 is primarily responsible for the biliary excretion of fexofenadine in mice. Drug Metab Dispos. 2008;36(1):61-4.

43. Matsushima S, et al. The inhibition of human multidrug and toxin extrusion 1 is involved in the drug-drug interaction caused by cimetidine. Drug Metab Dispos. 2009;37(3):555-9.

44. Matsushima S, et al. Involvement of multiple efflux transporters in hepatic disposition of fexofenadine. Mol Pharmacol. 2008;73(5):1474-83.

45. Cvetkovic M, et al. OATP and P-glycoprotein transporters mediate the cellular uptake and excretion of fexofenadine. Drug Metab Dispos. 1999;27(8):866-71.

46. Nozawa T, et al. Functional characterization of $\mathrm{pH}$-sensitive organic anion transporting polypeptide OATP-B in human. $\mathrm{J}$ Pharmacol Exp Ther. 2004;308(2):438-45.

47. Shimizu M, et al. Contribution of OATP (organic anion-transporting polypeptide) family transporters to the hepatic uptake of fexofenadine in humans. Drug Metab Dispos. 2005;33(10):1477-81.

48. Tian X, et al. Impact of basolateral multidrug resistance-associated protein (Mrp) 3 and Mrp4 on the hepatobiliary disposition of fexofenadine in perfused mouse livers. Drug Metab Dispos. 2008;36(5):911-5.

49. Moj D, et al. A comprehensive whole-body physiologically based pharmacokinetic model of dabigatran etexilate, dabigatran and dabigatran glucuronide in healthy adults and renally impaired patients. Clin Pharmacokinet. 2019;58:1577-93.

50. Tsuruya Y, et al. Different involvement of OAT in renal disposition of oral anticoagulants rivaroxaban, dabigatran, and apixaban. J Pharm Sci. 2017;106(9):2524-34.

51. Shen $\mathrm{H}$, et al. Renal excretion of dabigatran: the potential role of multidrug and toxin extrusion (MATE) proteins. Mol Pharm. 2019;16(9):4065-76.

52. Stangier J, et al. Pharmacokinetics and pharmacodynamics of the direct oral thrombin inhibitor dabigatran in healthy elderly subjects. Clin Pharmacokinet. 2008;47(1):47-59.

53. Troutman MD, Thakker DR. Efflux ratio cannot assess P-glycoprotein-mediated attenuation of absorptive transport: asymmetric effect of P-glycoprotein on absorptive and secretory transport across Caco-2 cell monolayers. Pharm Res. 2003;20(8):1200-9.

54. Shirasaka Y, et al. Species difference in the effect of grapefruit juice on intestinal absorption of talinolol between human and rat. J Pharmacol Exp Ther. 2010;332(1):181-9.

55. Aronson JK. Clinical pharmacokinetics of digoxin 1980. Clin Pharmacokinet. 1980;5(2):137-49.

56. US FDA. LANOXIN (Digoxin) Tablets. US FDA Product Insert.

57. Molimard M, Diquet B, Benedetti MS. Comparison of pharmacokinetics and metabolism of desloratadine, fexofenadine, levocetirizine and mizolastine in humans. Fundam Clin Pharmacol. 2004;18(4):399-411.

58. US FDA. ALLEGRA (fexofenadine hydrochloride) Capsules and Tablets. US FDA Product Insert.

59. US FDA. PRADAXA ${ }^{\circledR}$ (dabigatran etexilate mesylate) capsules for oral use. US FDA Product Insert; 2010.

60. Terhaag B, et al. The biliary elimination of the selective betareceptor blocking drug talinolol in man. Int J Clin Pharmacol Ther Toxicol. 1989;27(4):170-2.
61. Haustein KO, Fritzsche K. On the pharmacokinetics of talinolol, a new beta 1-receptor blocking agent. Int J Clin Pharmacol Ther Toxicol. 1981;19(9):392-5.

62. Acocella G. Clinical pharmacokinetics of rifampicin. Clin Pharmacokinet. 1978;3(2):108-27.

63. Westphal K, et al. Induction of P-glycoprotein by rifampin increases intestinal secretion of talinolol in human beings: a new type of drug/drug interaction. Clin Pharmacol Ther. 2000;68(4):345-55.

64. Greiner B, et al. The role of intestinal P-glycoprotein in the interaction of digoxin and rifampin. J Clin Investig. 1999;104(2):147-53.

65. Gurley BJ, et al. Gauging the clinical significance of P-glycoprotein-mediated herb-drug interactions: comparative effects of St. John's wort, Echinacea, clarithromycin, and rifampin on digoxin pharmacokinetics. Mol Nutr Food Res. 2008;52(7):772-9.

66. Hamman MA, et al. The effect of rifampin administration on the disposition of fexofenadine. Clin Pharmacol Ther. 2001;69(3):114-21.

67. Hartter $\mathrm{S}$, et al. Decrease in the oral bioavailability of dabigatran etexilate after co-medication with rifampicin. Br J Clin Pharmacol. 2012;74(3):490-500.

68. Lutz JD, et al. Cytochrome P450 3A induction predicts P-glycoprotein induction. Part 1: establishing induction relationships using ascending dose rifampin. Clin Pharmacol Ther. 2018;104(6):1182-90.

69. Rameis H. On the interaction between phenytoin and digoxin. Eur J Clin Pharmacol. 1985;29(1):49-53.

70. Bergen DC. Pharmacokinetics of phenytoin: reminders and discoveries. Epilepsy Curr. 2009;9(4):102-4.

71. Ahn JE, et al. Phenytoin half-life and clearance during maintenance therapy in adults and elderly patients with epilepsy. Neurology. 2008;71(1):38-43.

72. Wang $\mathrm{H}$, et al. Human constitutive androstane receptor mediates induction of CYP2B6 gene expression by phenytoin. J Biol Chem. 2004;279(28):29295-301.

73. Strandjord RE, Johannessen SI, Halpern LM. One daily dose of diphenylhydantoin for patients with epilepsy. Epilepsia. 1974;15(3):317-27.

74. Yamada S, et al. Effects of the P-glycoprotein inducer carbamazepine on fexofenadine pharmacokinetics. Ther Drug Monit. 2009;31(6):764-8.

75. Lutz JD, et al. Cytochrome P450 3A induction predicts P-glycoprotein induction. Part 2: prediction of decreased substrate exposure after rifabutin or carbamazepine. Clin Pharmacol Ther. 2018;104(6):1191-8.

76. Giessmann T, et al. Carbamazepine regulates intestinal P-glycoprotein and multidrug resistance protein MRP2 and influences disposition of talinolol in humans. Clin Pharmacol Ther. 2004;76(3):192-200.

77. Bertilsson L, Tomson T. Clinical pharmacokinetics and pharmacological effects of carbamazepine and carbamazepine-10,11-epoxide. An update. Clin Pharmacokinet. 1986;11(3):177-98.

78. Kuhnz W, et al. Carbamazepine and carbamazepine-10,11-epoxide during pregnancy and postnatal period in epileptic mother and their nursed infants: pharmacokinetics and clinical effects. Pediatr Pharmacol (New York). 1983;3(3-4):199-208.

79. Bertilsson L. Clinical pharmacokinetics of carbamazepine. Clin Pharmacokinet. 1978;3(2):128-43.

80. Chan KK, et al. Bioequivalence of carbamazepine chewable and conventional tablets: single-dose and steady-state studies. J Pharm Sci. 1985;74(8):866-70.

81. Faucette SR, et al. Relative activation of human pregnane $X$ receptor versus constitutive androstane receptor defines distinct 
classes of CYP2B6 and CYP3A4 inducers. J Pharmacol Exp Ther. 2007;320(1):72-80.

82. Dresser GK, et al. Coordinate induction of both cytochrome P4503A and MDR1 by St John's wort in healthy subjects. Clin Pharmacol Ther. 2003;73(1):41-50.

83. Mueller SC, et al. Effect of St John's wort dose and preparations on the pharmacokinetics of digoxin. Clin Pharmacol Ther. 2004;75(6):546-57.

84. Schulz HU, et al. Investigation of pharmacokinetic data of hypericin, pseudohypericin, hyperforin and the flavonoids quercetin and isorhamnetin revealed from single and multiple oral dose studies with a hypericum extract containing tablet in healthy male volunteers. Arzneimittelforschung. 2005;55(10):561-8.

85. Skinner MH, Blaschke TF. Clinical pharmacokinetics of rifabutin. Clin Pharmacokinet. 1995;28(2):115-25.

86. Wang SY, et al. Effect of quercetin on P-glycoprotein transport ability in Chinese healthy subjects. Eur J Clin Nutr. 2013;67(4):390-4.

87. Kim KA, Park PW, Park JY. Short-term effect of quercetin on the pharmacokinetics of fexofenadine, a substrate of P-glycoprotein, in healthy volunteers. Eur J Clin Pharmacol. 2009;65(6):609-14.

88. Moon YJ, et al. Quercetin pharmacokinetics in humans. Biopharm Drug Dispos. 2008;29(4):205-17.

89. Li L, et al. Bioactive terpenoids and flavonoids from Ginkgo biloba extract induce the expression of hepatic drug-metabolizing enzymes through pregnane $\mathrm{X}$ receptor, constitutive androstane receptor, and aryl hydrocarbon receptor-mediated pathways. Pharm Res. 2009;26(4):872-82.

90. He X, et al. Effects of curcumin on the pharmacokinetics of talinolol in human with $\mathrm{ABCB} 1$ polymorphism. Xenobiotica. 2012;42(12):1248-54.

91. Juan H, Jing T, Wan-Hua Y, Juan S, Xiao-Lei L, Wen-Xing P. P-gp induction by curcumin: an effective antidotal pathway. $J$ Bioequivalence Bioavailab. 2013;5(6):236-41.

92. Cheng D, et al. Pharmacokinetics, pharmacodynamics, and PKPD modeling of curcumin in regulating antioxidant and epigenetic gene expression in healthy human volunteers. Mol Pharm. 2019;16(5):1881-9.

93. Kluth D, et al. Modulation of pregnane X receptor- and electrophile responsive element-mediated gene expression by dietary polyphenolic compounds. Free Radic Biol Med. 2007;42(3):315-25.

94. Yamazaki S, Costales C, Lazzaro S, Eatemadpour S, Kimoto E, Varma MV. PBPK modeling approach to predict rifampinmediated intestinal P-glycoprotein induction. Clin Pharmacol Ther Pharmacom Syst Pharmacol. 2019;8(9):634-42.

95. Iisalo E. Clinical pharmacokinetics of digoxin. Clin Pharmacokinet. 1977;2(1):1-16.

96. Klotz U, Antonin KH. Biliary excretion studies with digoxin in man. Int J Clin Pharmacol Biopharm. 1977;15(7):332-4.

97. Caldwell JH, Cline CT. Biliary excretion of digoxin in man. Clin Pharmacol Ther. 1976;19(4):410-5.

98. Magnusson MO, et al. Pharmacodynamics of carbamazepinemediated induction of CYP3A4, CYP1A2, and Pgp as assessed by probe substrates midazolam, caffeine, and digoxin. Clin Pharmacol Ther. 2008;84(1):52-62.

99. Nishimura M, Naito S, Yokoi T. Tissue-specific mRNA expression profiles of human nuclear receptor subfamilies. Drug Metab Pharmacokinet. 2004;19(2):135-49.

100. Oscarson $\mathrm{M}$, et al. Transcriptional profiling of genes induced in the livers of patients treated with carbamazepine. Clin Pharmacol Ther. 2006;80(5):440-56.
101. Schwarz UI, et al. Induction of intestinal P-glycoprotein by St John's wort reduces the oral bioavailability of talinolol. Clin Pharmacol Ther. 2007;81(5):669-78.

102. Chrubasik-Hausmann S, Vlachojannis J, McLachlan AJ. Understanding drug interactions with St. John's wort (Hypericum perforatum L.): impact of hyperforin content. J Pharm Pharmacol. 2019;71(1):129-38.

103. Yu CP, et al. Quercetin and rutin reduced the bioavailability of cyclosporine from Neoral, an immunosuppressant, through activating P-glycoprotein and CYP 3A4. J Agric Food Chem. 2011;59(9):4644-8.

104. Wang $\mathrm{YH}$, et al. Lethal quercetin-digoxin interaction in pigs. Life Sci. 2004;74(10):1191-7.

105. Ha HR, et al. In vitro inhibition of midazolam and quinidine metabolism by flavonoids. Eur J Clin Pharmacol. 1995;48(5):367-71.

106. Elbarbry F, Ung A, Abdelkawy K. Studying the inhibitory effect of quercetin and thymoquinone on human cytochrome P450 enzyme activities. Pharmacogn Mag. 2018;13(Suppl 4):S895-9.

107. Raucy JL. Regulation of CYP3A4 expression in human hepatocytes by pharmaceuticals and natural products. Drug Metab Dispos. 2003;31(5):533-9.

108. Mitsunaga Y, et al. Effect of bioflavonoids on vincristine transport across blood-brain barrier. Eur J Pharmacol. 2000;395(3):193-201.

109. Ravikumar Reddy D, et al. Natural flavonoids silymarin and quercetin improve the brain distribution of co-administered P-gp substrate drugs. Springerplus. 2016;5(1):1618.

110. Zhang W, Lim LY. Effects of spice constituents on P-glycoprotein-mediated transport and CYP3A4-mediated metabolism in vitro. Drug Metab Dispos. 2008;36(7):1283-90.

111. Kusuhara $\mathrm{H}$, et al. Pharmacokinetic interaction study of sulphasalazine in healthy subjects and the impact of curcumin as an in vivo inhibitor of BCRP. Br J Pharmacol. 2012;166(6):1793-803.

112. Xiao CQ, et al. Effect of genistein on the activities of cytochrome P450 3A and P-glycoprotein in Chinese healthy participants. Xenobiotica. 2012;42(2):173-8.

113. Ellis LC, Hawksworth GM, Weaver RJ. ATP-dependent transport of statins by human and rat MRP2/Mrp2. Toxicol Appl Pharmacol. 2013;269(2):187-94.

114. Niemi M, et al. Association of genetic polymorphism in $\mathrm{ABCC} 2$ with hepatic multidrug resistance-associated protein 2 expression and pravastatin pharmacokinetics. Pharmacogenet Genomics. 2006;16(11):801-8.

115. Fromm MF, et al. The effect of rifampin treatment on intestinal expression of human MRP transporters. Am J Pathol. 2000;157(5):1575-80

116. Marschall HU, et al. Complementary stimulation of hepatobiliary transport and detoxification systems by rifampicin and ursodeoxycholic acid in humans. Gastroenterology. 2005;129(2):476-85.

117. Zhang W, et al. Role of BCRP $421 \mathrm{C}>\mathrm{A}$ polymorphism on rosuvastatin pharmacokinetics in healthy Chinese males. Clin Chim Acta. 2006;373(1-2):99-103.

118. Ho RH, et al. Effect of drug transporter genotypes on pravastatin disposition in European- and African-American participants. Pharmacogenet Genomics. 2007;17(8):647-56.

119. Yu Y, et al. Population pharmacokinetics of talazoparib in patients with advanced cancer. J Clin Pharmacol. 2020;60:218-28.

120. Nademanee K, et al. Amiodarone and thyroid function. Prog Cardiovasc Dis. 1989;31(6):427-37.

121. Su SF, Huang JD. Inhibition of the intestinal digoxin absorption and exsorption by quinidine. Drug Metab Dispos. 1996;24(2):142-7. 
122. Calvo MV, et al. Interaction between digoxin and propafenone. Ther Drug Monit. 1989;11(1):10-5.

123. Backman JT, et al. Concentrations and effects of oral midazolam are greatly reduced in patients treated with carbamazepine or phenytoin. Epilepsia. 1996;37(3):253-7.

124. Ucar M, et al. Carbamazepine markedly reduces serum concentrations of simvastatin and simvastatin acid. Eur J Clin Pharmacol. 2004;59(12):879-82.

125. Lee SD, Osei-Twum JA, Wasan KM. Dose-dependent targeted suppression of P-glycoprotein expression and function in Caco-2 cells. Mol Pharm. 2013;10(6):2323-30.

126. European Medicines Agency, Committee for Medicinal Products for Human Use. Talazoparib (Talzenna) Assessment Report; 2019. p. 58.
127. Rostami-Hodjegan A. Physiologically based pharmacokinetics joined with in vitro-in vivo extrapolation of ADME: a marriage under the arch of systems pharmacology. Clin Pharmacol Ther. 2012;92(1):50-61.

128. Pan Y, et al. The application of physiologically based pharmacokinetic modeling to predict the role of drug transporters: scientific and regulatory perspectives. J Clin Pharmacol. 2016;56(Suppl 7):S122-31.

129. Tubic M, et al. In silico modeling of non-linear drug absorption for the P-gp substrate talinolol and of consequences for the resulting pharmacodynamic effect. Pharm Res. 2006;23(8):1712-20. 